\title{
Lecturas desde el exilio: Luce Fabbri y la interpretación del totalitarismo europeo
}

\author{
Readings from exile: Luce Fabbri and the interpretation of \\ European totalitarianism
}

Ricardo O. Pasolini*

\section{RESUMEN}

El artículo analiza las ideas que la intelectual anarquista Luce Fabbri (1908-2000) desarrolló en su exilio montevideano acerca del fenómeno totalitario en Europa, al que le dedicó varios artículos en la revista Studi Sociali e incluso un libro de análisis publicado en Buenos Aires a mediados de la década de 1930. El caso es interesante por varias razones: permite observar el alcance y los tópicos del debate político transnacional del antifascismo italiano del momento; muestra la sustancialidad de un pensamiento personal que ha sido evaluado como continuidad de quien fuera su padre, el dirigente anarquista Luigi Fabbri, pero que tiene su particularidad e independencia interpretativa; devela el entramado de las relaciones globales de los exiliados quienes, desde las tierras de acogida, se interrogaron sobre las alianzas, la resistencia y las formas políticas futuras a la espera de la caída de los fascismos europeos.

\section{SUMMARY}

The article analyzes the ideas that anarchist intellectual Luce Fabbri (1908-2000) developed during her exile in Montevideo regarding the totalitarian phenomenon in Europe. She devoted several articles in the journal Studi Sociali and even a book of analysis published in Buenos Aires in the mid-1930s. The case is interesting for several reasons: it allows us to observe the scope and topics of the transnational political debate of Italian antifas-
Palabras clave:

Luce Fabbri, antifascismo, exilio, totalitarismo.

Keywords:

Luce Fabbri, antifascism, exile, totalitarianism.

\footnotetext{
* Argentino. Doctor en Historia, Instituto de Estudios Históricos y Sociales (IEHS). Instituto de Geografía, Historia y Ciencias Sociales (IGEHCS)/ Consejo Nacional de Investigaciones Científicas y Técnicas (CONICET), Universidad Nacional del Centro (UNICEN), Argentina. ORCID: https://orcid.org/0000-0001-8760-2968. E-mail: rpasolini@gmail.com
} 
cism at the time; shows the substantiality of personal thought evaluated as a continuity of her father, the anarchist leader Luigi Fabbri, but which has its particularity and interpretative independence; unveils the web of global relations of exiles who, from their host countries, questioned themselves about alliances, resistance, and future political forms while waiting for the fall of European fascism. 
Luce Fabbri (Roma, 1908-Montevideo, 2000) llegó a Montevideo en 1929, luego de terminar sus estudios universitarios de literatura italiana en la Universidad de Bolonia, donde había permanecido en casa de unos familiares luego de que su padre, el importante intelectual y dirigente anarquista Luigi Fabbri -en el marco de las persecuciones del fascismo-, optara por la alternativa de un exilio personal inicial y más tarde familiar que tuvo varias estaciones, primero en Francia y Bélgica, de donde fue expulsado, y después en Uruguay. A pesar de su juventud, Luce acompañó desde el inicio el proyecto editorial de la revista Studi Sociali ${ }^{1}$ con el que su padre intentó animar la discusión política del anarquismo y el antifascismo de la comunidad italiana emigrada en Francia, Estados Unidos, Argentina y Uruguay, aunque desde un espacio periférico como lo era Montevideo en la década de 1930.

Así y todo, la revista y el propio Fabbri lograron participar como interlocutores válidos de esa discusión en la red transnacional del antifascismo italiano exiliado, de tal suerte que no solo las referencias y polémicas evidenciaron las tensiones de la propia familia anarquista global, sino que también fueron claras en sus diálogos críticos con el novedoso movimiento socialista-liberal Giustizia e Libertà (1929), o con figuras del comunismo o socialismo intelectual a las que se les adjudicaba gran parte de las culpas que habían permitido el advenimiento del fascismo en Italia (Aldrighi, 1996: 5-8).

Cuando en 1935, y con 27 años, Luce asumió la dirección de Studi Sociali ante el fallecimiento de su padre, esta situación de interlocución se mantuvo sin sufrir deterioros significativos — solo fue más difícil mantener la periodicidad en la edición de la revista, en el marco de las restricciones que la presidencia interina de corte dictatorial de José Luis Gabriel Terra le impuso a la vida política uruguaya ${ }^{2}-$, a pesar de que la acción internacional del antifascismo italiano se vio fuertemente limitada y adquirió un carácter más defensivo, a raíz de la

1 La revista bimensual Studi Sociali se editó en Montevideo entre 1930 y 1946. Primero bajo la dirección del importante dirigente anarquista Luigi Fabbri, y a partir de 1935, a cargo de su hija Luce. Revista de ideas, de formación doctrinaria, y de análisis político global, Studi Sociali participó activamente tanto en los debates animados por la prensa anarquista internacional, como en los que se daban entre los diferentes grupos de la migración política italiana.

2 Durante la presidencia de Terra las ideologías profascistas y falangistas encontraron terreno fértil para su desarrollo (Bresciano, 2009: 95). 
profundización de antiguos procesos y de la aparición de novedades políticas: por ejemplo, el consenso general que la guerra en Etiopía le dio al fascismo italiano en el poder en la clave de la exaltación nacionalista (y a cómo se comportaron los gobiernos de los países antifascistas europeos ante esto); la implementación de las leyes raciales en 1938 -lo cual motivó la persecución y el exilio de un importante número de judíos italianos-; la derrota de los republicanos en España y el fracaso del Frente Popular francés; el Pacto Germano-Soviético, que significó hasta 1941 la pérdida de la URSS, el mayor exponente del antifascismo que contaba con una organización internacional; y el inicio de la Segunda Guerra Mundial (Rapone, 2002: 508). En fin, contextos nada favorables para la acción antifascista en general, y más aún para un grupo político que, si bien había alcanzado un renovado protagonismo internacional a partir del triunfo del Frente Popular español, se encontraba también en retirada y en minoría en la constelación global de las izquierdas, como lo era el anarquista.

\section{Luce Fabbri, exilio y antitotalitarismo}

El ejemplo de Luce Fabbri es significativo por varias razones y podría ser analizado desde aristas y perspectivas muy diversas, desde la más reciente historia transnacional del anarquismo (Margarucci, 2020), hasta la del exilio femenino y su potencial y particular modo de interrogar los discursos hegemónicos sobre el heroísmo de la militancia masculina (Martínez Martínez, 2019), la del antifascismo y su relación con la perspectiva de género (Richet, 2016) y la del pensamiento político de entreguerras, entre otras (Traverso, 2001). De alguna manera, y como lo han señalado los microhistoriadores, la reducción de la escala de análisis al nivel de los individuos resulta a veces la más compleja de las estrategias de investigación, pues la dimensión de planos que se entrecruzan en el intento de contar una vida podría volverse inconmensurable (Pasolini, 2019). Desde un punto de vista inicial y en función de problemas más amplios en mis investigaciones que vinculan el antifascismo italiano y sus lecturas antitotalitarias, el caso de Luce Fabbri es relevante en la clave de lo que Renato Camurri (2020: 126) ha llamado el giro "translocal" de los estudios sobre el exilio italiano del periodo de entreguerras, una perspectiva relativamente reciente en la historiografía del exilio de las capas intelectuales, menos atenta a las condiciones de expulsión o al problema del retorno a los países de ori- 
gen, y más enfocada en los procesos de inserción en las comunidades transnacionales receptoras, y en las contribuciones de los exiliados en una variedad diversa de campos culturales y disciplinarios, de tal suerte de poder delimitar la experiencia estricta del exilio (desplazamiento forzoso e imposibilidad de retorno) de la del fuoruscitismo (emigración política fundada en la incapacidad o limitación de la acción militante en el país de origen), procesos con raíces comunes pero no siempre equivalentes.

Sobre este punto, es necesario establecer algunas precauciones metodológicas que derivan también de la reducción de la escala de análisis al nivel del individuo y su ciclo vital, pues el uso de categorías muy cerradas limitaría a veces la identificación de la particularidad de los procesos que vinculan la migración económica, con la migración política y el exilio (Groppo, 1996: 27-35). Como ha demostrado Antonio Bechelloni (2001: 103-122), el estudio de los itinerarios personales y la construcción de biografías de los emigrantes y exiliados italianos en Francia, por ejemplo, ha permitido observar la complejidad de este fenómeno, mostrando que no pocas veces que los exiliados, luego de un tiempo de permanencia en la sociedad receptora, se convertían en emigrantes por causas económicas, mientras que, por el contrario, emigrantes económicos sin experiencia política previa descubrían o desarrollaban una identidad política antifascista a partir de su participación en organizaciones de resistencia. Es verdad, también, que en la categorización laxa de este autor se advierte una correspondencia muy estrecha entre la noción de "exiliado" y la de "emigrante político", presente también en gran parte de los trabajos sobre la temática, y que, sin duda, no se está refiriendo al cuerpo más reducido en número y más especializado profesionalmente, como el de los intelectuales exiliados.

En este sentido, cabe señalar que Luce Fabbri, quien permaneció en Uruguay hasta su fallecimiento, tuvo una importante participación en la enseñanza particular de la lengua italiana, el griego y el latín en Montevideo, antes restringida a los ambientes religiosos, participando también en los niveles secundarios de la educación pública y en el Instituto de Profesores Artigas, donde dictó Literatura Italiana e Historia de la Civilización Italiana entre 1950 y 1972. A partir de 1949 se incorporó como profesora de Literatura Italiana en la Universidad de la República, cargo que desempeñó hasta 1991, a excepción del periodo 
de cesantía que le impusieron las autoridades universitarias surgidas del golpe militar de 1974. El reconocimiento del cursus honorum en el ambiente académico, más su condición de mujer y libertaria, ha sido destacado como excepcional en los relatos biográficos que atienden su itinerario (Guzzo, 2014: 57-61).

Lo es también si se tienen en cuenta tanto otros aspectos biográficos, como la participación en un espacio social amplio de vínculos y referencias intelectuales, en la medida en que su trayectoria permite iluminar hasta dónde, en una periferia atlántica, era posible dialogar críticamente y propositivamente con los ambientes y los temas que dominaban en otras latitudes donde el debate del antifascismo se activaba, y que eran visualizados como referencias insoslayables, sea para filiaciones oportunas o distanciamientos programáticos. De allí su temprana participación en el periódico anarquista La Protesta, de Buenos Aires, sus conferencias sobre los orígenes del fascismo dictadas en el Colegio Libre de Estudios Superiores de Rosario durante los primeros años treinta, su papel colaborador primero y directriz después en Studi Sociali, la codirección de la revista Socialismo y Libertad (1943), y sus artículos en Volontà, la revista de posguerra dirigida por Giovanna Caleffi Berneri, viuda del importante intelectual anarquista Camillo Berneri, asesinado en Barcelona durante los penosos sucesos de mayo de 1937, en la que el pensamiento del anarquismo italiano intentó intervenir activamente en la discusión sobre el destino que debía tomar la Italia posfascista en el clima internacional de la Guerra Fría (Sacchetti, 2007: 77-78).

Por otra parte, la reflexión de Luce Fabbri entre 1935 y 1946 periodo en que estará a cargo de la dirección de Studi Sociali- opera también en momentos diversos del exilio antifascista italiano, uno en el que el antifascismo pareciera mantenerse defensivo y con bajas expectativas respecto de una potencial derrota del fascismo, y otro, a partir de 1943, en que el horizonte se presentará más promisorio, de tal suerte que permitirá pensar en escenarios de reconstrucción política para Italia y para Europa.

Sobre este punto en particular, algunas investigaciones recientes que vinculan la relación entre experiencias de exiliados judío-italianos y republicanos españoles, dan cuenta de cómo, en las tierras de acogida, un diálogo profundo se desarrolló desde la periferia atlántica, 
activando una red espacial amplia de relaciones personales e institucionales que fue desde Buenos Aires hasta México y Estados Unidos, posibilitando un proceso de hibridación intelectual que no siempre implicó una adaptación marginal de nociones políticas generadas en ambientes centrales de circulación de ideas, sino que alcanzó también aspectos creativos, originales y propositivos. Tal es el caso de la particular y anticipatoria idea de una "tercera vía" entre socialismo y democracia liberal, propuesta a partir del diálogo entre el sociólogo italiano Renato Treves y el exfuncionario de la República española y también escritor Francisco Ayala, exiliados en Argentina (Quaggio, 2020: 151178).

Del mismo modo, la incorporación de la noción de "totalitarismo" en el bagaje conceptual de Luce Fabbri, aunque se presente más tardía en su elaboración detallada (1945), va a responder, en primer lugar, al influjo transnacional que la reflexión antifascista alcanzó hacia mediados de los años treinta, instancia en la que también irrumpe esta noción todavía imprecisa en el debate político amplio de la emigración, y que alcanzará su momento cúlmine en el clima de la Guerra Fría. Y, en segundo lugar, al funcionamiento de una red americana del exilio antifascista que dio como resultado la constitución del grupo Socialismo y Libertad, un espacio antitotalitario que vinculó a socialistas, liberales, republicanos y anarquistas de México, Argentina, Chile y Uruguay en la común preocupación política sobre la discusión del destino de Europa.

Más allá de estos diferentes momentos antifascistas, para Luce Fabbri la etapa defensiva significó también una oportunidad de elaboración de un pensamiento propio, de desafío personal, de protagonismo organizativo e intelectual, y, en algún sentido, de búsqueda de la propia voz autoral en un marco personal y familiar caracterizado, por un lado, por la experiencia nodal del exilio, y, por otro, por un vínculo muy intenso con su padre, expresado no solo en el plano de la natural e inocultada afectividad filial, sino también en la común pertenencia ideológica. En este sentido, no parece extraño que la dedicatoria con la que Luce Fabbri da inicios al libro de poemas I canti dell'attesa (Los poemas de la espera), publicado en Montevideo en 1932, enfatice con la fórmula: "A mio padre, l'amico mio, il mio compagno nello studio e nella battaglia". Tono que se repetirá a lo largo de las futuras ediciones de Studi Sociali luego de la muerte de Luigi, incluso en los últimos 
números de la revista hacia 1946. Y que se cristalizará como exegesis última en la biografía Luigi Fabbri, storia d'un uomo libero, de 1996.

Continuidad afectiva y mitología familiar que ha llevado a sostener en algunos estudios más o menos recientes, una también continuidad interpretativa entre Luigi y Luce respecto de sendas lecturas de la experiencia fascista (Minuto, 2018: 85-94; Garay Montaner, 2012: 115). Tema de mi interés e interpretación que intentaré contextualizar en este artículo, proponiendo la hipótesis de que si en algunas dimensiones es posible observar esa continuidad, en el momento de la publicación de su artículo "Il totalitarismo fra le due guerre" (Fabbri, 1945: 10-19) se advierten novedades interpretativas que dialogan con un espectro de referencias intelectuales mayor al provisto por el anarquismo internacional (o su filiación parental inmediata), en particular, la incorporación de la noción de totalitarismo y la extensión del concepto no solo a la experiencia nazifascista sino también a la soviética.

Por otro lado, no está demás mencionar que el tema de la especificidad política del fascismo y de su permanencia histórica animó gran parte de las reflexiones de Luce Fabbri a lo largo de su dilatada vida intelectual, construida particularmente en Montevideo, pero ligada tanto afectiva como políticamente al debate italiano, aun después de la caída del fascismo. Tal interés, que recorre la casi totalidad de sus producciones, comenzó de manera más sistemática en 1934 con la publicación en Buenos Aires de su libro Camisas Negras (editado por la revista anarquista Nervio), continuó con el artículo mencionado sobre el totalitarismo (1945) -que en 1948 se convirtió, con algunas modificaciones, en un libro-y prosiguió con el opúsculo "El fascismo, definición e historia, publicado en Montevideo en 1963”. En este sentido, no hubo en Luce, como tampoco en el conjunto de la emigración política italiana del periodo de entreguerras, una ruptura con la cultura de origen que se acercara a la experimentada por los exiliados judíoalemanes de perfil intelectual emigrados en Estados Unidos. Ni siquiera en el caso de los judíos italianos, que debieron optar por el exilio en Argentina a raíz de la implementación de las leyes raciales de 1938, se verifica un fenómeno equivalente. Si bien para estos la relación con Italia fue contradictoria, entre Italia y el fascismo era posible establecer una distinción animada por las diferentes formas de resistencia que se desarrollaban tanto en las comunidades del exilio, como las que se 
estaban dando en el interior mismo de Italia. Por otro lado, los judíos italianos estaban muy asimilados a la cultura laica y humanista en la península, de manera tal que la construcción de su identidad, como lo ha señalado el historiador de origen judío Arnaldo Momigliano, exiliado en Gran Bretaña, no había estado en una tensión particular con el propio proceso de desarrollo de una conciencia nacional italiana, o en todo caso no había sido diferente de las elaboradas en la clave de los regionalismos siciliano, piamontés o napolitano (Pasolini, 2001: 176177).

Los intelectuales judío-alemanes exiliados en Europa o Estados Unidos, por su parte, no pudieron dejar de identificar Alemania con el nazismo, cortando todo vínculo incluso lingüístico y cultural, (Palmier, 1988: 376). De allí que no parezca extraño que una de las razones del retorno de Theodor Adorno a Alemania en 1965, se fundara también en el hecho de la nostalgia del uso de su lengua materna.

Luce Fabbri, en cambio, continuó escribiendo en su lengua de origen, interpeló también con nostalgia y emotividad su etapa formativa en Bolonia y su experiencia vital en Italia, geografía que recorrió de norte a sur siguiendo el trayecto de los diferentes traslados de su padre maestro, dan cuenta de ello I canti dell'attesa, y, más allá de su internacionalismo libertario, no dejó nunca de referenciarse en el debate político italiano (Fabbri, 1955).

En síntesis, el análisis del artículo de 1945 se revela importante no solo por su novedad interpretativa, sino porque ilustra el modo en que, desde una periferia intelectual, la vivencia del exilio exigió - en el caso de Luce Fabbri- un permanente intento de actualización conceptual, de entendimiento de una realidad política global y, por ende, de un diálogo con las otras familias ideológicas del antifascismo italiano, como por ejemplo, con el movimiento Giustizia e Libertà, creado por el intelectual socialista-liberal Carlo Rosselli, al que la unía una común defensa del liberalismo político. Un diálogo que, si bien no desconocía los intentos de resistencia interna en la península, aún en pleno auge del fascismo, estuvo casi exclusivamente circunscrito a las comunidades emigradas, en tanto que el fenómeno del antifascismo italiano fue sobre todo una cultura del exilio. Fue en ella donde se desarrolló la noción de la pervivencia exterior de "un'altra Italia", una reserva de civilización, en su doble sentido de cultura cívica y patrimonio cultural 
humanista (Traverso, 2003: 72) que esperaba el momento en que el fascismo en la península fuera derrotado, tanto por la acción resistente de un pueblo considerado siempre como potencia emancipatoria y portador de un antifascismo existencial, como por el fuoruscitismo organizado.

\section{Entre el anarquismo y Giustizia e Libertà}

¿Qué plantea entonces Luce Fabbri en su artículo sobre el totalitarismo europeo de entreguerras? Para responder esta pregunta resulta necesario relevar en principio el contenido de sus interrogaciones sobre el origen y la composición del fascismo, que se iniciaron en una serie de conferencias dictadas en Argentina y publicadas posteriormente. En efecto, en el libro Camisas Negras (Fabbri, 1934) Luce recurre en un modo interpretativo dominante a la tesis enunciada por su padre en el libro que publicara en Bolonia en 1922, respecto del fascismo italiano como "contrarrevolución preventiva" (Fabbri, 2009: 29 y ss.), esto es, la del fascismo como una respuesta política a la intervención de Italia en la Gran Guerra y a los fermentos emancipatorios obreros que le siguieron, y que, a juicio de Luigi, requirió de la reacción de la clase dirigente, entendida ésta no solo como la burguesía capitalista sino también como la de los sectores ligados a las prebendas del Estado, desde el empresariado hasta los trabajadores de las clases medias bajas. Para Fabbri padre el fascismo ilustra como reacción la continuación de la guerra por otras vías, en la que se expresaba ante todo la lucha de clases.

El fascismo no podía ser reducido exclusivamente a la burguesía, pero expresaba sus intereses defensivos. En este sentido, el final de la guerra de 1914-1918, que implicó la beligerancia entre las naciones, se tradujo en el interior de las sociedades en el aumento de las tensiones entre fascistas y socialistas, para Fabbri, la tensión natural entre la burguesía y el proletariado, sobre todo porque la clase obrera había alcanzado, muy por encima de las dirigencias partidarias, una cierta unanimidad en su posicionamiento conflictivo. Esto habría sido particularmente notable en Italia, de tal suerte que, para él, el componente emancipatorio ensayado por el proletariado italiano había estado muy por encima de la por entonces reciente experiencia soviética, acerca de la cual -en la lectura de un anarquista crítico como lo era Fabbri- no 
podía decirse todavía que la implementación del socialismo de Estado tuviera efectos positivos sobre el ideal de la libertad humana que el anarquismo perseguía.

Esta interpretación, en el momento mismo en que el fascismo se está gestando con éxito como organización política en Italia, no excluía el reconocimiento de la especificidad nacional del proceso de gestación, como tampoco una mirada más general del fenómeno que veía en la reacción antiobrera una característica propia de las sociedades modernas. Así y todo, y en un modo explicativo un tanto arbitrario, la experiencia de la guerra seguía teniendo para Fabbri un papel develador de la conflictividad estructural moderna, no solo por la cantidad de naciones implicadas en la contienda bélica, sino porque la guerra era presentada como el resultado del temor a la organización proletaria y su fermento revolucionario, y a la vez como una causa concomitante del surgimiento de fascismo, precisamente para evitar que ese fermento tuviera éxito.

Si en este punto Fabbri se aleja de la interpretación leninista de la Gran Guerra como guerra imperialista, la lectura del fascismo como respuesta política de la clase conservadora elaborada por el comunismo internacional durante el periodo de entreguerras se le acerca visiblemente.

El temor a la revolución en ciernes, entonces, fue lo que motivó la reacción de las fuerzas conservadoras: "S'è avuta cosi la contro-rivoluzione senza rivoluzione, una vera e propria contro-rivoluzione preventiva, di cui il fascismo e stato il fattore piu attivo ed impresionante" (Fabbri, 2009: 45).

El análisis de Luce Fabbri continúa en su base esta línea interpretativa, y le suma otros elementos contextuales: en primer lugar, el reconocimiento de que la necesidad de estudiar el origen del fascismo italiano se volvía más perentoria aún a partir de la emergencia y el triunfo del nazismo en Alemania, presentado como un hijo directo del primero. En segundo lugar, la identificación de la atmósfera cultural de preguerra, animada por cierta sensibilidad refractaria hacia los principios amplios de 1789 que, según Luce, "se habían vulgarizado y parecían vulgares" para unas elites intelectuales "que no [tenían] que luchar por la vida y se [creaban] motivos de lucha, a veces artificiales, 
en el campo de las ideas" (Fabbri, 1934: 56-57). Así, sobre la base de la desacreditación de la experiencia democrática, del cientificismo, de los valores de libertad y racionalidad, la débil ideología inicial del fascismo se caracterizó por la exaltación de ciertos tópicos, como la pasión política, el irracionalismo, el activismo, el espíritu de rebeldía, que tenían además un componente lírico, un idea estética y muy sugerente de la acción política, pero en absoluto revolucionaria. Sin embargo, para Fabbri estos elementos no constituían el contenido ideológico sustancial del fascismo, que era:

"esencialmente una defensa armada de los privilegios de una clase y que no tiene otro programa real que la voluntad de dominio. El fascismo surgió como antidemocracia, porque la democracia ya no servía para defender el mundo capitalista; pero tuvo necesidad de buscarse un sistema y de fabricarse precursores, para atraer a la juventud descontenta y también a cierta clase de intelectuales" (Fabbri, 1934: 20).

Que en ese momento Luce recurriera a esta interpretación, habla a las claras de la matriz de su formación y también de la escasa difusión que para 1934 tenían otras interpretaciones en danza sobre el origen del fascismo italiano, elaboradas por ejemplo por integrantes del movimiento Giustizia e Libertà desde París a través de los Quaderni di Giustizia e Libertà publicados entre enero de 1932 y enero de 1935. Curiosamente, esta revista, animada por el socialista liberal Carlo Rosselli, solía contar con la colaboración de Luigi Fabbri, y circulaba aunque con retraso en el mundo de la emigración política rioplatense. En todo caso, si la accesibilidad material estaba disponible, su incorporación conceptual e intelectual todavía se veía limitada. De hecho, una reseña de Camisas Negras, publicada en 1935 en el semanario parisino Giustizia e Libertà, aunque no descontaba elogios sobre la calidad narrativa del libro y sobre la identificación que Luce hacía en él de los pilares del sostenimiento fascista (el Estado, la Iglesia católica, y el capitalismo), reconocía algunas deficiencias que debilitaban su argumentación: la falta de incorporación de documentación producida por el propio régimen y la ausencia en el análisis de los elementos festivos y de impacto popular que movilizaban a las masas hacia el fascismo. También, un cierto convencionalismo abstracto que el reseñista atribuyó a la distancia entre el análisis fáctico requerido y la memoria juvenil de los 
tiempos en que Luce Fabbri vivía en Italia y había sido testigo, y a la vez víctima, del proceso de advenimiento y consolidación del fascismo (Giua, 1935: 2).

Para este grupo y para algunos de sus intelectuales, el fascismo italiano debía ser pensado primero como autobiografía de la nación, como patología enraizada en la inmadurez del proceso histórico de la unificación italiana, y luego como crisis moral total de la cultura cívica europea. La novedad que llevaba a esta última conclusión era el triunfo del nazismo a partir de 1933, lo cual quitaba del marco nacional italiano, en primer lugar, la periodización del fenómeno fascista: ya no era un efecto localizado de la Gran Guerra, sino de las consecuencias morales, económicas y políticas de las fuerzas desatadas y no controladas del siglo XIX europeo, que habían generado ante todo la existencia de una masa informe y disponible compuesta por marginales y desplazados, considerada la base social del fascismo. Y, en segundo término, su extensión espacial, pues se verificaba que muchos gobiernos tendían al fascismo o a ciertas formas autoritarias de ejercicio del poder, inaugurando así un clima de época definido como "totalitario". Esto es, procesos políticos generales caracterizados por la reducción total de la experiencia cívica y personal bajo la tutela y la acción de los gobiernos, enmarcada en unas categorías y fuerzas integradoras supraindividuales, como la nación, el imperio, el Estado, la raza y la guerra ${ }^{3}$.

\section{La degeneración totalitaria}

Luce Fabbri no advierte estas novedades interpretativas en su libro de 1934, que habían llevado en París a fuertes polémicas en el seno de las diversas familias políticas del exilio antifascista. Por cierto, no todas las agrupaciones coincidían en ver en el origen del fascismo una patología del proceso risorgimentale italiano, o en excluir como definitoria la dimensión económica del fenómeno ${ }^{4}$. Sin embargo, esas novedades estarán más presentes en su artículo de 1945, aunque en Studi Sociali de 1941, ante una evaluación del fracaso revolucionario en España y del papel jugado por la URSS desde el pacto germano-soviético, Luce

3 He intentado desarrollar un análisis exhaustivo del impacto atlántico de las ideas del movimiento Giustizia e Libertà en la emigración política italiana en Pasolini (2021). 4 La mayor disidencia respecto de este punto la expresó el jurista republicano Silvio Trentin, integrante también de Giustizia e Libertà (Trentin, 1931: 11-16). 
ya había anticipado opiniones equivalentes a las de algunos integrantes de Giustizia e Libertà sobre el totalitarismo. Al menos, comienza a advertirse una ampliación de su significación original en su uso de la noción "totalitarismo", antes exclusivamente asociada con las experiencias fascistas italiana y alemana. No es posible precisar en detalle el momento en que este cambio se verifica, pues entre agosto de 1939 y enero de 1941 Luce Fabbri no logra publicar los números esperados de Studi Sociali.

Varios elementos coadyuvan a ello: la elaboración de la revista está exclusivamente en sus manos; el inicio de la guerra ha cortado la mayoría de los circuitos internacionales de su circulación, de modo que comienza a preguntarse si el esfuerzo requerido para editarla encontrará interlocutores accesibles, y, por último, una "difficile maternità", que la obligó a prolongar casi al absoluto el tiempo de ocio (Fabbri, 1941: 2). Es interesante señalar en este punto que desde $I$ canti dell'attesa no se observaba en las elaboraciones de Luce Fabbri una referencia a dimensiones más íntimas y personales, más allá de que siempre su lugar de enunciación en el campo de las ideas y de los posicionamientos fue muy visible, sea a través de su nombre propio como con el seudónimo Lucia Ferrari, con el que también solía publicar en Studi Sociali.

Lo cierto es que en su artículo "Il cadavere e il mostro", de febrero de 1941, la correspondencia entre fascismo y comunismo como fenómenos totalitarios se presenta ya como una constatación. Para el movimiento Giustizia e Libertà el pacto germano-soviético había significado la muerte de la revolución, o al menos de lo que la URSS representaba como modelo de sustitución de progreso de la humanidad. Más allá de que muchos miembros de GeL habían manifestado tempranamente sus reservas respecto de la experiencia comunista rusa (y en ese punto sus cercanías con la lectura anarquista resultaban evidentes), era posible establecer una distinción entre la revolución y la dictadura de Stalin, y al mismo tiempo, pensar en los comunistas como potenciales aliados en una lucha antifascista que había adquirido alcances internacionales, en particular a partir de 1935.

Para Luce Fabbri, en cambio, el pacto no fue otra cosa que una continuidad de procesos en la que - en tiempos de capitalismo internacionalizado y de economía dirigida - el fascismo exaltó el mito ex- 
pansionista de la nación y del imperio, y el comunismo el mito del proletariado. Ambos ya no se correspondían con la realidad, según Luce, y menos aún el segundo, convertido ahora en un instrumento del Estado soviético que sustituyó a partir de él toda dimensión revolucionaria de la clase obrera (Ferrari, 1941: 1-2). Continuidad, por un lado, y constitución de un nuevo orden, por el otro, caracterizados por la centralidad del Estado y por la debilidad democrática: "Il totalitarismo fascista, nazista, sovietico (tre nomi: una sola sostanza) può durare; la democrazia borghese no. Se il privilegio non può sussistere se non trasformandosi in totalitario, la democrazia non può sopravvivere se non trasformandosi di liberale in libertaria" (Ferrari, 1941: 2).

Está claro que, como en muchos de quienes asumieron posiciones activas en la militancia del exilio, también en Luce Fabbri la reflexión sobre la situación política mundial estuvo no solamente fundada en un propósito de ilustración personal y colectiva - recurriendo a herramientas intelectuales en función de un perfil de formación y de inserción personal en el campo del anarquismo-, sino, sobre todo, por la búsqueda de orientación para la acción política concreta. No se trató de especulaciones ociosas. Por ello en sus análisis no estuvo ausente, además de las dimensiones propositivas para las organizaciones anarquistas, la evaluación del lugar de los otros actores del antifascismo y la identificación de los tópicos que ella consideraba claves para entender el nuevo orden en tiempos de guerra mundial. De allí que el propósito de la recuperación de la libertad política apareciera como primordial. Es en este marco que, en 1945, el tema del totalitarismo adquiere en Luce una centralidad argumental en sus análisis políticos, una operación que se realiza a partir de al menos tres instancias: el tamiz de un sustrato de ideas anarquistas clásicas le permitió elaborar una crítica inicial de los Estados fuertes; la cercanía con el ideario liberal -fuera este último la variante socialista-liberal de Rosselli como aquella más clásica de Benedetto Croce (quien pareciera seguir siendo el árbitro en la discusión política italiana a partir de 1943)— le posibilitó establecer un diálogo político sobre la noción de libertad individual y existencia del Estado, sin dejar de proponer la distinción fuerte entre socialismo liberal y socialismo libertario; por último, su participación más específica en la red del exilio europeo antiautoritario, que dio como resultado en 1943 la constitución americana del movimiento Socialismo y Libertad. 
En efecto, con su centro más dinámico en México, lugar donde se habían refugiado Víctor Serge, Marceau Pivert, Julian Gorkin, Leo Valiani, Gustav Regler y Ricardo Mestre, entre otros importantes referentes del socialismo, el republicanismo y el anarquismo internacional, desde Montevideo Luce Fabbri se va a convertir en la codirectora de la revista también llamada Socialismo y Libertad, que se editada en español, francés e italiano.

Responsable de la sección italiana, junto al también anarquista Torquato Gobbi, antiguo colaborador de Luigi Fabbri, Luce participó de este modo en un circuito intelectual que pugnaba, más allá de sus diferencias, por la construcción de la unidad de una Europa posfascista que surgiera de los horrores de la guerra. Si bien la sección uruguaya duró poco y solo alcanzó a publicar seis números de la revista, se advierte también allí el elevado consenso y la importancia que la discusión del tópico antitotalitario había alcanzado en estas familias políticas, del mismo modo que en aquellas publicaciones con las cuales se mantenían fuertes vínculos, como Mundo, la revista mexicana del grupo SyL, Claridad de Buenos Aires, y la Partisan Review norteamericana (Albertani, 2008/2009: 133). Claro que, en la reflexión de este movimiento, no solo se alcanzó el acuerdo sobre la cuestión totalitaria, sino también sobre el contenido anticapitalista de la futura organización europea que se proponía, a lo que Luce le sumó, siguiendo los argumentos de Serge, Gorkin y Pivert ${ }^{5}$, la propuesta de la "abolizione dello Stato" (Fabbri, 1945a: 25).

De acuerdo con el argumento central de Luce Fabbri, la elección del periodo de entreguerras como una unidad histórica respondía a la

5 Víctor Serge (Víctor Lvóvich Kibálchic) fue un publicista e intelectual de origen belga que participó en el proceso de la Revolución Rusa, convirtiéndose luego en uno de los críticos más acérrimos del estalinismo, lo cual provocó, a mediados de los años treinta, su encarcelamiento por parte de las autoridades rusas, y el surgimiento de un movimiento internacional que pidió por su liberación. Marceau Privet formó parte de la Section française de l'Internationale ouvrière (SFIO). Durante el gobierno del Frente Popular Francés, se colocó en posiciones de izquierda revolucionaria que lo llevaron a polemizar con el gobierno de Leon Blum, y a abandonar luego la SFIO. Julián Gorkin (Julián Gomez García) fue un militante y publicista español que transitó varias organizaciones políticas de corte revolucionario hasta llegar a formar parte activa del POUM en los tiempos de la Guerra Civil Española. Todos ellos se encontraron en el exilio mexicano y elaboraron un conjunto de reflexiones más radicales que incluían influencias no orgánicas del trotskismo, el anarquismo y el llamado marxismo libertario, que se oponía al difundido por la Komintern. 
identificación de un proceso particular, pero éste no era como lo habían pensado los contemporáneos:

"la rivoluzione russa, ma la degenerazione totalitaria di quella stessa rivoluzione e la formazione progressiva, lenta e confusa [...] dei regimi totalitari in Occidente. Il totalitarismo è la controrivoluzione, a posteriori in Russia, preventiva negli altri paesi. Parallelamente al processo totalitario, abbiamo un processo rivoluzionario, schiacciato dapertutto dopo il grandioso balzo della Russia del 1917, però non vinto, come sè veduto in Francia nel 1936, nella rivoluzione spagnola del 1936-39 e come si stà vedendo ora in tutta Europa" (Fabbri, 1945b: 10).

En efecto, luego de desarrollar un análisis de las condiciones y causas estructurales que llevaron a la Gran Guerra, esta vez en una interpretación muy cercana a la de Lenin en tanto guerra imperialista, y la identificación de distintos momentos en el fascismo europeo, uno más propiamente preventivo y de reacción ante la amenaza de la beligerancia proletaria, y otro surgido de la crisis económica de 1929, Luce Fabbri enfoca su observación en el factor que considera más importante: el proceso revolucionario en Rusia, pues a partir de él y sus resultados se puede comprender mejor el paralelismo y la contradicción que llevaron al occidente europeo a consolidar lo que en la Europa del Este se había destruido: la propiedad privada. Con la revolución y la implementación del equívoco concepto de "dictadura del proletariado", lo que se constituyó fue una dictadura de partido que ocupó el puesto del antiguo Estado, y asumió un carácter más centralizado aún, convirtiéndose así en un Estado propietario. Dice Luce: "Infatti la propietà privata era stata abolita e la gestione della produzione e della distribuzione, che sembraba destinata a rimanere nelle mani dei soviet di produttori e consumatori, fu monopolizzata dal partito dominante e centralizzata nello Stato" (Fabbri, 1945b: 13).

El resultado fue la consolidación de una burocracia de partido, engrosada con el tiempo por técnicos que se convirtieron en la nueva clase dominante de un nuevo tipo de Estado empresarial, basado también en una organización jerárquica. Sin olvidar, claro está, la instancia de la sistematización de la represión estatal, pues para Luce la organización económica del Estado ruso iba de la mano del dominio absoluto de la persona política. En ese sentido, el totalitaris- 
mo ruso era igual a la contrarrevolución, la negación misma del socialismo. Un socialismo que, en su concepción, era entendido como las formas colaborativas que tendían al desarrollo de la potencialidad del individuo, a partir de la liberación inicial que los condicionamientos materiales le imponían. De hecho, tanto en Luce como en gran parte del pensamiento anarquista, la alusión a la noción de "clase obrera" como destinataria privilegiada de su acción política está bastante menos presente que la de "individuo" y su "libertad personal". De allí su cercanía al pensamiento de Carlo Rosselli, quien en su Socialisme libéral (1930) propuso nociones equivalentes. También su insatisfacción con la explicación exclusivamente economicista del funcionamiento social, incluso con cierta antropología filosófica que atribuía al hombre una búsqueda constante de acumulación de bienes y goces materiales. Para Luce, la voluntad de dominio, el deseo de poder era lo que movía existencialmente al hombre, y un Estado que dominaba y oprimía era la forma en que ese deseo se expresaba en el momento totalitario de mundo.

Lo interesante de este argumento, sin la pretensión de establecer con ello una idea de causalidad, aunque sí de la existencia de un ambiente facilitador de circulación, préstamos y recreación de ideas, es que de algún modo anticipa con bastante cercanía lo que la crítica liberal anticomunista de los tiempos de la Guerra Fría dirá sobre el Estado soviético.

Al ejemplo soviético de totalitarismo, Luce contrapone el del nazismo alemán, sin dejar de remarcar que entre este último y el fascismo italiano había algunas diferencias de tono, periodización, beligerancia e intensidad, pero que participaban de una misma familia política, aunque el primero condensara en un breve periodo lo que incluso al fascismo italiano le había llevado mayor tiempo desarrollar: una idea - la de la diferenciación y la particularidad de los fascismos- que había sido expuesta tempranamente en el artículo revelador que Nicola Chiaromonte había publicado en Quaderni di Giustizia e Libertà (Chiaromonte, 1935), y que, para el momento, gozaba de gran aceptación en el mundo de la emigración política italiana.

Aparece así en la argumentación de Luce Fabbri la noción de "capitalismo de Estado" para ilustrar ese momento en que se consolida el corporativismo en la organización del capital y el trabajo; se rigidizan 
todas las funciones e instituciones de la vida pública; se promueve un clima de guerra para militarizar a las masas. De allí la incursión italiana en Abisinia, de allí también la premisa totalitaria alemana, que pasó de la idea de partido único de Estado a "Stato unico nell mondo [...]. In Germania s'è operato fácilmente il passaggio dall'idea di una casta privilegiata nella nazione a quella del popolo privilegiato in una terra senza frontiere" (Fabbri, 1945b: 15). Sin olvidar el componente racista y el nacionalismo, pero evaluándolos siempre como instrumentos de un sistema de proyección exterior y de unificación interna al servicio del salvataje del principio de autoridad y de jerarquía en los tiempos de la crisis del capitalismo privado.

Luce Fabbri continúa su evaluación del periodo de entreguerras, señalando que las oportunidades perdidas para los procesos revolucionarios estuvieron íntimamente relacionadas con este clima totalitario, que aún en experiencias como las del Frente Popular francés llevaron a considerar como legítimo el principio de la colaboración entre las clases y el paternalismo de Estado. Y que, en el caso de la República Española, el temor a una revolución popular triunfante inhabilitó el apoyo que tanto Inglaterra como Francia podrían haber dado. De allí que España se convirtiera casi exclusivamente en una tierra de disputa entre los totalitarismos ítalo-alemán y ruso.

En este sentido, el inicio de la Segunda Guerra Mundial fue para Luce el resultado de dos tendencias: una - en la que se hallaba también la Guerra Civil española - tenía sus antecedentes en la lucha antifascista que se había iniciado en 1922, con el advenimiento del fascismo en Italia. La otra oponía a la vieja clase capitalista en decadencia contra el "troppo invadente e prematuramente universalista totalitarismo tedesco". Así y todo, para el momento de elaboración del artículo, la lectura de los tiempos de dopo-guerra que Luce avizora se presenta más promisoria, en parte porque considera inevitable la derrota del "Impero hitleriano". También porque las nuevas fuerzas que resultarán triunfantes, la demoplutocracia americana y europea, y el totalitarismo ruso, no impedirán que la verdad de la España de 1936-1939 salga a la luz, con su mensaje antiestatalista. Pero, sobre todo, porque advierte en las manifestaciones de resistencia clandestina de los países implicados en la guerra y en las comunidades del exilio transnacional una común disposición a vincular sin conflicto - como lo era en la tra- 
dición anarquista - los tópicos socialismo, colectivismo y federalismo con liberalismo político y cultural.

"Il nuovo antifascismo conoscerà forse più d'una sconfitta parziale.

Potrà evitare la sconfitta definitiva solo se saprà situarsi su questo terreno socialista libertario su cui molte delle sue forze più pure già si trovano. È l'ideale per cui ha lottato nove anni fa la Spagna rivoluzionaria, per cui sono morti Schirru e Durruti, Berneri e Rosselli, è oggi, per quanto spesso inconsapevole, l'ideale dell'avanguardia rivoluzionaria europea" (Fabbri, 1945b: 18-19).

\section{Reflexiones finales}

El escenario relativamente positivo que se cierra con el artículo de 1945 asume otro carácter en su reedición como opúsculo de 1948, el cual reproduce in toto los contenidos originales, pero le suma una conclusión desesperanzadora que los acontecimientos de posguerra la llevan a considerar. El resultado inmediato de la derrota del nazismo no se orientó en un sentido libertario, sino que profundizó su carácter totalitario. En todas partes, afirma ahora Luce, el Estado tiende a hacerse total, en todas partes los monopolizadores del Estado tienden a hacer de éste su instrumento, transformándose ellos mismos en sus engranajes.

Las democracias surgentes lo son porque respetan las formas electorales, pero las dosis de liberalismo son cada vez más limitadas, al igual que las declamaciones políticas de los partidos y el internacionalismo socialista. Por su parte, los partidos socialistas europeos se verán en la alternativa de caer o en el bolchevismo autoritario o en la corriente antiestalinista que inevitablemente resultará en el apoyo a las reformas de las democracias burguesas, cuya única alternativa de sostenimiento se conducirá al mantenimiento del capitalismo de Estado. En el medio, en el caso italiano, la polarización entre las ideas del totalitarismo estalinista y el supuesto liberalismo cristiano, nociones que a juicio de Luce no pueden existir fuera del control estricto de sendas iglesias: el Estado ruso y el Vaticano.

Claro, que entiende que luego de las privaciones de la guerra y la experiencia de las tiranías, el pueblo de Europa se vea estimulado solo por el reclamo inicial de pan y libertad, en una situación en la 
que las organizaciones políticas no están en condiciones de asegurar aún. Todo ello en un contexto de polarización del mundo en el cual el peligro factual de una nueva guerra, esta vez atómica, no se descarta. Una guerra y una crisis capitalista que no ha alcanzado aún a América Latina del mismo modo en que lo hizo en Europa, pero que podría resultar un ejemplo útil para pensar el modo de combatir a "sus Perones, a sus democracias dominadas por el dólar, a sus Lombardos Toledanos (...) mirando más allá de los fenómenos contingentes" (Fabbri, 1948: 19 y ss).

En síntesis, estas reflexiones y escritos de Luce Fabbri que recurrieron a la noción de "totalitarismo" ilustran una de las formas en que ese concepto fue incorporado como palabra clave del análisis político de la situación europea a partir de mediados de los años 30. Luce lo hizo en un modo particular, que dialogó también con las tradiciones de pensamiento propias del anarquismo y con las estimulaciones que provenían de los ambientes amplios del exilio y la migración política que caracterizaron al antifascismo de entreguerras.

Más allá de que el propósito que guiara el análisis de Luce Fabbri estuviera en función del posicionamiento del anarquismo en el escenario político de la segunda posguerra, su reflexión no deja de evidenciar un modo de búsqueda de una propia voz autoral - femenina, punzante, libertaria y novedosa- en el marco de la también difícil experiencia personal y existencial del exilio.

\section{Referencias bibliográficas}

\section{Fuentes secundarias}

\section{a) Artículos y capítulos de libros}

Albertani, C. (2008/2009). "Socialismo y Libertad. El exilio antiautoritario de Europa en México y la lucha contra el estalinismo, 1940-1950", en Políticas de la Memoria, pp. 131-133.

Aldrighi, C. (1997). “Luigi Fabbri en Uruguay, 1929-1935”, en Estudios Migratorios Latinoamericanos, $\mathrm{N}^{\circ} 12$, pp. 389-422.

Bresciano, J. A. (2009). "El antifascismo ítalo-uruguayo en el contexto de la Segunda Guerra Mundial", en Deportate, esuli, profughe, $\mathrm{N}^{\circ} 11$. 
Bechelloni, A. (2001). "Au croisement des parcours migratoires et des engagements militants: antifascistes italiens en France entre le Front populaire et la Libération", en Devoto, F. y P. González Bernaldo, Émigration politique: une perspective comparative. Italiens et Espagnols en Argentine et en France (XIXe-XXe siècles). Paris: CEMLA-L'Harmattan, pp. 103-122.

Camurri, R. (2014). “The exile experience reconsidered: a comparitive perspective in european cultural migration during interwar period", en Transatlantica. Revue d'études américaines, $\mathrm{N}^{\circ} 1$, pp. 4-8.

Camurri, R. (2020). "Introduction. Exile: an accelation towards modernity", en Annals of the Fondazione Luigi Einaudi, Vol. LIV, pp. 121-128.

Chiaromonte, N. (1935). "La morte si chiama fascismo", en Quaderni di Giustizia e Libertà, $\mathrm{N}^{\circ} 12$, pp. 20-60.

De Maria, C. (2016). "Camillo Berneri, un intelectual de frontera. Tres itinerarios de lectura”, en M. Fuentes Cordera, A. Duarte \& P. Dogliani, Itinerarios reformistas, perspectivas revolucionarias. Zaragoza: Institución "Fernando El Católico".

Fabbri, Luce (1937a). "Sui diversi fronti: Camillo Berneri", en Studi Sociali, $\mathrm{N}^{\circ} 6$, pp. 4-6.

Fabbri, Luce (1937b). "Sui diversi fronti: Carlo Rosselli", en Studi Sociali, $\mathrm{N}^{\circ} 7$, pp. 3-4.

Fabbri, Luce (2 maggio 1939). "Primo bilancio d'una sconfitta”, en Studi Sociali, $\mathrm{N}^{\circ} 13$, pp. 1-2.

Fabbri, Luce (1941a). “Ai compagni”, en Studi Sociali, N 15, pp. 2-3.

Fabbri, Luce (1941b). “La nostra guerra”, en Studi Sociali, № 1, pp. 1-3.

Fabbri, Luce (1945a). "Benedetto Croce. Il socialismo liberale e il socialismo libertario", en Studi Sociali, № 4, pp. 21-25.

Fabbri, Luce (1945b). "Il totalitarismo tra le due guerre", en Studi Sociali, $\mathrm{N}^{\circ} 4$, pp. 10-19.

Fabbri, Luce (1948). "El totalitarismo entre las dos guerras", en Cuadernos de Cultura Social, $\mathrm{N}^{\circ} 1$. Buenos Aires: Ediciones Unión Socialista Libertaria.

Fabbri, Luce (1955). "Sotto la minaccia totalitaria", en Democrazia, Liberalismo, Socialismo, Anarchismo. Napoli: Edizioni RL.

Ferrari, Lucia (1937). “Bisogna dirlo”, en Studi Sociali, Nº 6, pp. 1-3. 
Ferrari, Lucia (1941a). "Il cadavere e il mostro", en Studi Sociali, N 15 , pp. 1-2.

Ferrari, Lucia (1941b). "Entra in scena la Russia”, en Studi Sociali, N ${ }^{\circ}$ 16 , pp. 1-2.

Giua, R. (1935). “Un libro di Luce Fabbri”, en Giustizia e Libertà, № 12, p. 2.

Groppo, B. (1996). "Entre immigration et exil: les réfugiés politiques italiens dans la France de l'entre-deux-guerres", en Materiaux pour l'histoire de notre temps, $\mathrm{N}^{\circ} 44$, pp. 27-35.

Leiva, M. L. (2019). "El debate sobre el fascismo, la guerra y el postfascismo en el exilio italiano en Argentina", en XVII Jornadas Interescuelas/Departamentos de Historia. Catamarca: Editorial Científica Universitaria. Universidad Nacional de Catamarca, pp. 11-13.

Margarucci, I. (2020). "Repensando el anarquismo en América Latina. $¿$ Del nacionalismo metodológico a un giro transnacional incompleto?", en Prohistoria, $\mathrm{N}^{\circ} 34$, pp. 249-280.

Martínez Martínez, A. (2019). "Las mujeres recuerdan. Género y memoria del exilio republicano en Francia, 1939-1978", en Arenal, Vol. 26, $\mathrm{N}^{\circ}$ 2, pp. 367-398.

Minuto, E. (2018). "La famiglia Fabbri e gli anni dell'esilio (1927-1935)", en De Maria, C. y E. Betti, Biografie, percorsi e networks nell'Età contemporanea. Un approccio transnazionale tra ricerca, didattica e Public History. Roma: BraDypUS, pp. 85-94.

Pasolini, R. (2001). "Exil italien et antifascismes en Argentine dans les années 30: la place des intellectuels", en Devoto, F. y P. González Bernaldo, Émigration politique: une perspective comparative. Italiens et Espagnols en Argentine et en France (XIXe-XXe siècles). Paris: CEMLA-L'Harmattan, pp. 176-177.

Pasolini, R. (2010). "The antifascist climate and the Italian intellectual exile in interwar Argentina", en Journal of Modern Italian Studies, Vol. 15, ${ }^{\circ}$ 5, pp. 693-714.

Pasolini, R. (2019). "Biografía y prosopografía. Cuestiones historiográficas y de método", en C. Salomón Tarquini et al., El hilo de Ariadna: propuestas metodológicas para la investigación histórica. CABA: Prometeo Libros, pp. 95-106.

Pasolini, R. (2021). "Antifascismo global y debates italianos sobre el totalitarismo: las ideas y los ecos atlánticos del grupo Giustizia e 
Libertà, 1932-1944", en Vicente, M. y M. López Cantera, La Argentina y el siglo del totalitarismo. CABA: Prometeo, pp. 25-51.

Quaggio, G. (2020). “The diaspora effect: cultural hybridisation in Italian Jewish philosopher Renato Treves and Spanish republican essayist Francisco Ayala in Argentina, 1938-1944", en Annals of the Fondazione Luigi Einaudi, Vol. LIV, pp. 151-178.

Rapone, L. (2002). "L'antifascismo tra Italia ed Europa", en Italia Contemporanea, $\mathrm{N}^{\circ} 229$, pp. 571-591.

Richet, I. (2016). "Women and antifascism. Historiographical and methodological approaches", en García, H., M. Yusta Rodrigo, X. Tabet, y C. Clímaco, Rithinking antifascism: history, memory and political uses, 1922 to the present. New YorkOxford: Berghahn Book, pp. 152-166.

Sacchetti, G. (2007). “Giovanna Caleffi Berneri redattrice di «Volontà». Lineamenti di un contributo teorico (1946-1962)", en F. Chessa, Giovanna Caleffi Berneri e la culura eretica di sinistra nel secondo dopoguerra. Reggio Emilia: Biblioteca Panizzi, pp. 77-78.

Scarzanella, E. (2011). "Ricordi di famiglia: l'antifascismo dei padri immigrati e la militanza rivoluzionaria dei figli (Uruguay, 19301980)", en Confluenze. Rivista di studi iberoamericani, Vol. 3, $\mathrm{N}^{\circ} 1$, pp. 83-94.

Traverso, E. (2003). "Los intelectuales y el antifascismo. Por una historización crítica”, en Acta Poetica, $\mathrm{N}^{\circ}$ 42-2, pp. 51-72.

b) Libros

Aldrighi, C. (1996). Antifascismo italiano en Montevideo. El diálogo politico entre Luigi Fabbri y Carlo Rosselli. Montevideo: Departamento de Publicaciones. Facultad de Humanidades y Ciencias de la Educación (UdeLar).

Fabbri, Luce (1932). I canti dell'attesa. Montevideo: M. O. Bertani Editore.

Fabbri, Luce (1934). Camisas negras. Estudio crítico histórico del origen y evolución del fascismo, sus hechos y sus ideas. Buenos Aires: Nervio.

Fabbri, Luce (1963). El fascismo. Definición e historia. Montevideo: Departamento de Publicaciones. Universidad de la República.

Fabbri, Luce (1996). Luigi Fabbri. Storia d'un uomo libero. Pisa: Biblioteca Franco Serantini. 
Fabbri, Luigi (2009). La controrivoluzione preventiva. Riflessioni sul fascismo. Milano: Zero in Condotta.

Garay Montaner, G. (2012). Anarquismo y utopía en el pensamiento de Luce Fabbri y Rafael Barret. Montevideo: Facultad de Humanidades y Ciencias de la Educación.

Guzzo, C. (2014). Libertarias en América del Sur: de la A a la Z. Buenos Aires: Libros de Anarres.

Palmier, J. M. (1988). Weimar en exil. Le destine de l'émigration intellectuelle allemande antinazie en Europe et aux États-Unis. Paris: Payot.

Rago, M. (2002). Entre la historia y la libertad. Luce Fabbri y el anarquismo contemporáneo. Montevideo: Nordan.

Rosselli, C. (1930). Socialisme libéral. Paris: Valois.

Traverso, E. (2001). El totalitarismo. Historia de un debate. Buenos Aires: Eudeba.

Trentin, S. (1931). Aux sources du fascisme. Paris: Marcel Rivière. 